\title{
CONTENT, IDENTITY BUILDING AND NATIONAL CURRICULA
}

\author{
Urve Läänemets \\ Estonian Academy of Music and Theatre
}

\section{Katrin Kalamees-Ruubel}

Estonia

\begin{abstract}
Theoretical research on curriculum development and implementation has been a rich and highly diverse field of study in the second half of the $20^{\text {th }}$ century and the first decade of the $21^{\text {st }}$, including Estonia, but the selection of educational content for general comprehensive schools has not been a priority. Some reasons for difficulties with regard to making informed decisions about the selection of the content can be found in the constantly growing amount of new knowledge, global developments and in cultural differences within and between societies. The acknowledged political goal for organising general education for the majority of countries in Europe (and all over the world) has been the development of a cohesive and sustainable society, which can be built on acknowledged and accepted common values. Research on the potential of school subjects can contribute to that and open new vistas for development of national curricula.
\end{abstract}

Keywords: content of education, identity building, national curriculum, school subjects, values

\section{Introduction}

According to "Europe 2020. A European Strategy for Smart, Sustainable and Inclusive Growth" (2010), a cohesive society can be built on acknowledged and accepted common values, which all its members may recognise in somewhat different individual value hierarchies, but they are still derived from a common comprehension of basic truths needed for identifying oneself with particular social groups, society at large and even globally.

We may claim that students' socialisation and identity development can be supported by a professionally selected and rationally integrated content of education (Hand book of Socialisation 2007). Only educated people can create a basis for the cohesion, sustainability and development of a society. National curricula for provision of general education that specify the basic content of learning/educational activities deserve particular attention as means of schooling for all the population. Various school subjects have different potential for widening learners' horizons by providing knowledge, for supporting the development of their skills for critical and creative thinking, and for helping them to find out with whom they identify themselves, by making informed decisions that will enable them to find their place in society in their future lives. National Curricula for general comprehensive schools of 2011 is to provide environments for such developments at compulsory schools as well as in 
gymnasia. Individual successful identity building would presumably bring about a coherent set of steps toward greater maturity (Maccobi 2007:17) for becoming an informed and critically thinking citizen.

The research aim was to find answers to the question: how could general comprehensive education better support development of students' individual value-based identity building for participation in a cohesive society. Research questions were the following:

1. What has influenced the development and diverse interpretations of the concept of identity in modern educational discourse?

2. What is the potential of different school subjects in the Estonian National Curricula (NC) for the identity development and socialisation of students?

3. How do students start to comprehend different identities and prioritise them from his/her own position as a developing personality?

The methods used for the study were: analysis of documents, semistructured interviews, focus group interviews and expert evaluations.

\section{Collected data and results}

The selection of the NC documents covers all of those that existed between 1917 and 2014. From the analysis of these documents, data were collected that characterised the development of identity building aspirations and the development of the scope of the concept over time as well as its interpretations in curricula. The analysis of educational goals and the selection of the content of different school subjects in the curricula allowed it to be ascertained whether and how much attention was paid to the development of students' identity building in the national curricula during the period of study. In all the NC documents of the Republic of Estonia between 1917-1940 the aspiration to support development of the national identity building can be observed, which has been especially stressed in the syllabi of the mother tongue Estonian, literature, music and history. During the WW II and the Soviet period (19401991) no holistic NC for general comprehensive schools were used, there were so-called subject program documents, which were periodically updated, and followed a different ideological trend aimed at development of the common Soviet nation. As expected, the new NC of 1996 and 2002 and the most recent NC documents of 2011 have in particular concentrated on values related to Estonian statehood, citizenship and culture in the globalised world and as a member of the EU.

Initial pilot interviews were carried out with the following target groups in 2010-2011: students and teachers, politicians and educational leaders (selected at random). Participation in the Jaan Tõnisson Institute project "Border Crossings, Moving Borders: Young peoples' constructions of identities in the Baltic countries in the early $21^{\text {st }}$ Century" (March 2010) provided invaluable insights into the processes of students' identity building in all the three Baltic 
countries and their attempts to specify the values their identities could be built on and how these young peoples' ideas are socially constructed: through social interaction, in a social context It should be emphasised that the aim of the study was not attempting to achieve a representative sample, but to identify the diversity of views expressed. There were 2 focus groups of 5-6 students (aged 13-14 and 15-16) from each of the 4 Estonian schools $(n=44)$, which provided us with the preliminary data for research question 3. In a focus group, the researcher introduced a few open-ended questions, and encouraged the students to discuss these between them so that they are interacting with each other, rather than with the researcher. As an example of this, the groups discussed what makes them Estonian (or Latvian or Lithuanian). They were using ideas, language, and vocabulary of their own choosing, rather than responding to the interviewer. The researcher is non-directive in such interviews - elucidating, guiding, but not focusing or constraining. The discussion points put were broad:

- How would you describe your identity? (if necessary, prompting with "What do you all have in common?", or, when [Estonian] was suggested, "What does being [Estonian] mean to you?")

- Do you ever describe yourselves in other ways, or feel you have difficulties always using this identity?

- Do you think your parents feel the same way about this as you?

- Do you think everyone in Estonia feels the same way?

- How does being in Europe affect the way you think about your identity, and about your future?

- What is particular or different about Europeans?

According to Ross (2010), identities are increasingly recognised as being both multiple and constructed contingently. Such identities may include a range of intersecting dimensions, including gender, age and region. It appears that a growing number of young people in parts of the European Union are acknowledging an at least partial sense of European identity alongside their national identity: the degree to which this is acknowledged varies by nationality, gender and social class, as well as by age. European and national identities are not alternatives, but potentially complementary feelings that can be held in parallel. The question is, what this multiplicity means for the young people involved and how this relates to the presence of the same two components in their identification with their country. The culture of Europe was less apparent in the young people's talk than was their reference to the civic practices of Europe. In particular, there were many references to the possibility of travel to other European states, and of studying and working there. Many of them, particularly the older students, said that they had considered higher education outside their own country, very often in other European Union states. They seemed well aware of the possibilities and options, as they were of the issues concerning work in other, generally western, European countries. 
Generally, most young people were more talkative about their own country, rather than Europe. There were many references to the national language, which for many was one of the defining facets of their unique cultural identity: "Our language is one of the oldest languages in Europe, and it's hard to learn it - so in languages we are different from other countries." - "We speak in Estonian", said Anett L (Estonian ${ }^{\circ} 13^{1 / 4}$ ) Estonia also had young people who were positive about their cultural identity, but others who were less articulate or more critical references. For example, Mikk N ( $\left.\delta^{\lambda} 13^{1 / 4}\right)$ was broadly positive about his Estonian heritage, but less able to identify its characteristics:

Estonians like singing and dancing. We have dance festivals and song festivals... Bread - we have black bread, and I think that it's the world's best

bread. I think my parents like it that Estonia is free. I see them happy when they talk about Estonia when it's a free country, and they think it's good.

Other young Estonians were even less articulate: asked "What does Estonia as a state mean to you?" Anet K (Estonian $\delta$ 13) can only respond "I just don't know." Taavi S ( 0 13) defines Estonia as "a small country", and recognises that "I don't think my parents understand things the same way: ...they know the history much better." Kaija M ( $\hat{O} 16)$ is ambivalent, to her Estonians:.. are depressed or something ... when I go to somewhere else, and meet people on the street, they smile always, they say hello, even if they don't know you ...but in Estonia, people are so... It's a small country, it's nice ...we should try and find something positive! My parents don't mind being Estonians, but they hate living in Estonia. Estonian students also held their national civic institutions and practices in low esteem. There were many complaints about national politics, for example, Liisi N ( ${ }^{\circ} 13^{1 / 4}$ ) was articulate about her concerns:

I don't like politics. Politics and politicians, both. They're terrible. Sometimes

I look at the news and read the paper, and I get this bad impression. The election commercials say "Oh, it will be so good! We are making it all great!"

And smarter people than them are saying that it's not possible, and they are lying, and they are just trying to sell themselves.

Opinions of teachers $(n=8)$, educational leaders $(n=5)$ and politicians $(5)$ on the same issues were collected by semi-structured interviews in February-May 2011. Earlier expert evaluations of field specialists $(n=47$, collected by questionnaires in 2000-2003 at Jaan Tõnisson Institute) analysing the potential of particular fields of knowledge were also used (Läänemets 2003). The teachers and educational leaders also stressed the value of the Estonian language, literature, history, music and knowledge about Estonian culture in general, whereas politicians stressed the new meaning of the Estonian history, Estonian as the official language and the language of instruction at schools.

The collected data allowed a preliminary and tentative specification of the factors for comprehending the meaning of different identities, considering the selected content of school subjects in the $\mathrm{NC}$, the organised/experienced process 
of learning and the socio-culturally specific circumstances - the real life and functioning of a society within a global context. While most students in all three countries saw themselves as having multiple identities, there were differences in the way that this was expressed. Factors in formal and informal education can influence the comprehension of identities (acceptance or rejection) and determine the effect of accepted identities on decision making for the development of the educational policy for the country.

\section{Discussion: Opportunities of general education for identity building}

The meaning of identity for organising education. Development of identities forms the basis for socialisation of individuals into their respective environments, social, cultural, natural, global, etc. creating cohesive societies. Comprehension of different interpretations of the concept and of these most complex processes of identity development may help make more informed decisions for organising public education, especially that provided by general comprehensive schools (Kim 1994, Hall 2003, Winterson 2001). Prislin \& Crano (2008) consider the development of attitudes as a primary stage of identity development.

The development of identities and awareness of self is especially important in childhood; it starts with development of attitudes and depends on the physical, emotional and cognitive interaction between the child and his or her social environment. In other words, everything starts in the home, which is where human relations and primary attitudes develop. The comprehension of values is usually based on knowledge and the motivation to inquire and learn about things comes later. Independent and conscious comprehension/formation of identities based on informed decision-making takes place subsequently, usually considerably later, at school age. The formation of identities is a lifelong process that is influenced by numerous, often unpredictable, factors. The number of established (or accepted) identities and their hierarchies (prioritised by the meaning they hold for an individual) may change considerably in this process.

Young people need knowledge and skills for critical thinking, and the same knowledge and skills are required for making decisions later in different life situations. The reason why countries all over the world aspire to develop knowledge-based societies is self-evident: the best and most rational decisions are usually made by knowledgeable people. It is crucial that individuals establish their basic values, as they lay the foundations for emotional and social belonging and for the primary identities in the hierarchy of senses of belonging. Usually the primary identities are those related to family and friends, which are cherished, long lasting and carefully preserved. Job-related contacts, on the other hand, may create several new identities in modern project-based life, but these are usually short-lived and easily lost.

Identities are created as shared values and expressed by a deliberate wish to 
belong to a particular group. By identification with the group a new social position is acquired: it means being recognised and accepted by the desired group of specific people sharing common values. When some identities are established, others of less value are lost and unacceptable identities are rejected simultaneously. Independent decision-making about what to accept or reject presumes the ability to think critically which progresses with learners' individual intellectual and social development. Therefore, different educational systems, institutions and curricula as professionally designed "plans for learning" (Taba 1962) specifying the educational content and providing guidance for selection of learning activities are compiled according to stages of human development ( e.g. pre-school, primary, secondary or tertiary education).

Considering our constantly changing environments (e.g. social, cultural, physical) we have to accept the fact that individual different hierarchies of identities are also dynamic in character. Young people in particular need information about the changes, and therefore the curricula for general comprehensive schools have to be regularly analysed and updated to meet the educational demands of a society. Outdated content has to be replaced by new and more pertinent modern knowledge. However, the old and valuable must be preserved. The cohesion of a society requires all its members to share some basic social identities as commonly accepted values. Estonia needs goal-oriented value education, which would help to strengthen both Estonian national and common European identities and which would avoid conflicts between different identities. The process of globalisation, the development of information technology and an intensifying mobility of people in the global labour market or for study have considerably increased the requirements of individuals to belong to more numerous, diverse and short-lived social groups. It also implies a need for clearer individual specification of different identities and their hierarchies that may also be in the process of continual change.

To conclude, compulsory education as a part of general comprehensive education is of particular significance as an environment supporting personality development, which is generally expected to produce an educated citizenry and a cohesive society with a sustainable economy and a progressive culture. Despite effects of globalization, for small nations, even in the 21 st century, national identity building is significant as a means for preserving and developing a particular culture, as a part of the global cultural heritage. Karseth and Sivesind (2011) support the idea by presenting an alternative understanding:

...continents and countries renew their traditions and curriculum designs to respond to global expectations. Cultural heritage is considered as an important source in two respects. Personal identity is developed by becoming familiar with inherited forms of conduct, norms of behaviour and modes of expression to become cultivated. The curriculum should therefore develop the learner's familiarity with national and local traditions. In addition, if society is going to remain democratic,the curriculum must play a leading role in passing the 
common cultural heritage (Karseth, Sivesind 2011:62).

The development of desirable identities leading to sustainable, cohesive and progressive societies is the primary task of compulsory education, and schools would be most effective if they could build on what has already been achieved at home and in pre-school institutions. All of the worthy aspirations of schools are manifested in the $\mathrm{NC}$, according to the content of which particular identities are expected to be established and others rejected. However, there is a "hidden curriculum" that exists in addition to the official NC: everyday life equally powerful with its unwritten but strictly observed laws and rules. The media and information technology are perhaps its most conspicuous manifestations, but we should not underestimate the impact of economic and political developments, globalisation, new discoveries, etc. A hidden curriculum may support or hamper the aspirations of schools.

When designing educational policy for a country, it is essential to comprehend that the general comprehensive school can and must provide the basic means of identity formation for all students. School subjects (or variously organised study units) disseminate through their content meaningful information for identity formation. Each subject contains carefully selected and specific information - a piece of cultural memory - for different school grades and levels of education, without which it is impossible to understand the values around us or to visualise and design future pathways for the society and the individual. Therefore, it is advisable to recognise and identify the potential influence of a single school subject, as well as that of the $\mathrm{NC}$ as a whole, and also that of the "hidden curriculum", on the development of desirable identities in a society. The importance of the content of general education for the sustainability and progress of any society has been recognised by members of different educational cultures. (Hopmann, Riquarts 2000:9). In some educational systems, specific identities are developed by indoctrination, which usually creates counter-effects. A prominent example of this phenomenon is the development of a resistance culture in Estonia and other Baltic countries. It explains the failure of Soviet education policy, which aimed at the establishment of a common but uniform nation. When educational policy is put into practice according to the principles of an democratically accepted ideology, then the establishment of individual identities is more diverse and varied in their hierarchies.

School subjects and their potential for identity building. Data collected by pilot interviews and expert opinions as well as analyses of theoretical literature and $\mathrm{NC}$ documents revealed that more attention should be paid to the selection of the content, which would support the establishment of the primary identities required for social cohesion and for the development of educated and responsible citizens who are able to preserve and enhance Estonian culture and to participate in international economic and cultural communication.

Studies should begin with the cycle of language subjects and its most basic foundation - the Estonian mother tongue -, which is of critical importance for 
small ethnic cultures. The native language and culture best unite the people of a country. Common cultural concepts create a unifying sense of shared identity and belonging to a society. There is a clear boundary between ethnic identity and the languages that other ethnic groups may use for communication. It operates at both the individual and collective levels of a group identity. We also need to consider how we interpret other people's identities based on their manner of speech (Joseph, 2004:28).

Mother tongue is the most essential prerequisite for cognition, thinking and learning and the most important subject in a national school. It is both - a school subject to be mastered and a means of learning (the language of instruction for other subjects). Estonians have always treasured schooling in their native language, good communication skills and ethnic culture, especially its written texts. Language has been a very special issue for us; especially under different and difficult social and political regimes, it has been a guarantee of sustainability as an ethnic group and culture. From the point of view of linguodidactics, mother tongue creates the foundations for learning all subsequent foreign languages and cultures, which in turn facilitate fluent communications in the globalised world. The potential of the mother tongue for individual identity formation as a means of establishing a cohesive society deserves particular attention; the acquisition of the content of other school subjects would also contribute to a correct and stylistically high-quality use of the language as well as comprehension of literature as a form of artistic expression of the language.

Music has always been a "second mother tongue" for Estonian schools. Learning about ethnic culture, listening to and making music can establish extremely strong identities. Music is not only just a means for developing a general comprehension of culture, for young people today it has become the basis for establishing diverse social identities (as witnessed in the different forms and styles of popular music). The meaning and opportunities of music has recently become a research field in human geography; study is being focussed on the "strong links between music and the sense of place and identity, both of people and places" (Hudson 2006:30). Again, it is advisable to consider the wider potential of music education for the establishment of social identities that transcends its traditional borders.

Science subjects related to nature, such as biology, chemistry and physics, have occupied an important position in the Estonian NC for a long time, especially up until the 1990s, probably due to a traditional and emphatic respect for home and nature, which has in turn created a specific environmental identity (Loorits, 1932, Jüssi et al, 2009). There used to be a traditional sequence of learning about the environment, which started with so-called studies about the home and local environment and was followed by botany, zoology and anatomy, integrated with geography, biology, chemistry and physics. This established a logical system for understanding the environment and opportunities for ecological and sustainable living being mindful of available resources. We now 
have to pay more attention to the principles of "green living" when selecting the content of science subjects; this would help students to understand global natural processes as well as mankind's responsibility to protect the environment both locally and globally. The role of mathematics as a means of identity development has not yet been widely researched, but it has unique potential (Sowell 2005). Math creates the foundations for logical and critical thinking, which allow us to comprehend the world as a whole, understand different systems and make informed decisions. The potential role of math in culture and in the curriculum development is considerably more significant than has been considered to date.

It is most challenging to find rational solutions to the establishment of social identities within the cycle of social studies subjects, especially history (Vickers 2005). Green, Janmaat et al (2009) have discussed three versions of social cohesion. In addition to the traditional history and civics, new school subjects have emerged, e.g. family education, health education, street law, and consumer education. In the modern globalised world, a new concept intercultural identity - has emerged, which supersedes at a meta-level the social identities related to one's primary culture and native country. This type of identity has created a basis for active mobility in the labour market and also for pursuing university studies abroad. Knowledge as a basis for identity building is seen as becoming an increasingly important source and a driving force for individual societal success within a society which is ever more complex and diverse (Karseth \& Sivesind 2011:64)

\section{Conclusion and proposals}

A national curriculum for general comprehensive schools as the primary document specifying the content of education creates a distinctive resource for a developing personality by providing information about the environment and future opportunities during the process of learning. However, acquired knowledge and skills and an understanding of real life are not the only factors that influence students' decisions about which identities to select or reject. Identities will be established according to accepted values based on acquired knowledge providing adequate arguments for a critically thinking individual, and these, in turn, provide people with a sense of belonging. Positive identity is a value in itself to comprehend and feel; it is a treasure that allows the individual to solve problems and resolve dissonances, and to meet his own expectations as well as those of the people closest to him. Identities and their hierarchies are actually values accepted as a result of ethical orientations and critical thinking. Schools have much to contribute to the development of an autonomous personality and self-awareness, if the $\mathrm{NC}$ is professionally and rationally compiled. Then the system of general education can meet the changing social demands for education, use the time allotted for studies rationally and support the establishment of identities required for social cohesion. In addition to the 
indispensable analysis of research literature and curricula of different countries, it is necessary to begin in-depth studies of the possibilities for identity development. In order to expand the potential of particular school subjects, we have an acute need for comparative curriculum research (primarily on aims and content) and comparative analyses of the monitoring results from their implementation in countries with similar cultural and social contexts (including the history of the region, languages spoken and religion). At the same time, longitudinal /regular research on the growing social demands for education must be conducted, which can provide arguments for modifying the $\mathrm{NC}$ and, if the need for the development of specific identities arises, for introducing new or updated educational content. Those responsible for curriculum development for general comprehensive schools are facing a serious ethical task with regard to making decisions on educational opportunities for all individuals in a society. Education will always be a moral enterprise. (Pinar 2012)

\section{References}

European Commission. (2010). Europe 2020. A strategy for smart, sustainable and inclusive growth. Brussels: European Commission.

Handbook of Socialization. Theory and research. (2007). J. E. Grusec, P. D. Hastings (Eds.). New York, London: The Guilford Press.

Green, A., Janmaat, J. G., Han, C. (2009). Regimes of Social Cohesion. Discussion Paper. Centre for Learning and Life Chances in Knowledge Economies and Societies, Institute of Education, University of London, London.

Hall, S. (2003) Who needs identity? In Questions of cultural identity. S. Hall, P. Du Gay (Eds.), pp. 1-17. London: Sage.

Handbook of Socialization. Theory and research. J. E. Grusec , P. D. Hastings (Eds.), pp. 1341. New York, London: The Guilford Press.

Hopmann, S., Riquerts, K. (2000). Starting a Dialogue: A Beginning Conversation Between Didaktik and the Curriculum Theory. In: Teaching as a reflective practice. The German Didaktik Tradition. I. Westbury, S. Hopmann, K. Riquerts (Eds.), pp. 3-11. Mawah, New Jersey, London: Lawrence Erlbaum Associates, Publishers.

Hudson, R. (2006). Regions and place: music, identity and place. In Progress in Human Geography, Vol 30, No 5, pp. 626-634.

Joseph, J. E. (2004). Languge \& Identity. National, Ethnic, Religious. London: Palgrave MacMillian.

Jüssi, F., Ott, U. (2009). Mister Fred. Esseed, artiklid, märkmed. Tallinn: SE\&JS.

Kim, Y. Y. (1994). Beyond cultural identity. In Intercultural Communication Studies IV:1.

Loorits, O. (1932). Eesti rahvausund. (Estonian folk religion, in Estonian). Elav Teadus nr 12. Tartu: Eesti Kirjanduse Selts.

Karseth, B., Sivesind, K. (2011). Conceptualising curriculum Knowledge within and Beyond the National Context. In: World yearbook of Education 2011.

Läänemets, U. (2003). Report of the project "VIPs on education. Experts about the knowledge for the Estonian National Curriculum". Manuscript. Tallinn: Jaan Tõnisson Institute.

Maccobi, E. (2007). Historical overview of socialisation. Research and theory. In Handbook of Socialization. Theory and research. J. E. Grusec, P. D. Hastings (Eds.) pp. 13-41. New York, London: The Guilford Press. 


\section{SOCIETY. INTEGRATION. EDUCATION. Volume II}

Pinar, W. F. (2012). The Character of Curriculum Studies. Bildung, Currere, and the Recurring Question of the Subject. New York, Palgrave Macmillan.

Prislin, R., Crano, W. D. (2008). Attitudes and attitude change. The Fourth Peak. In Attitudes and attitude change. W. D. Crano \& Radmila Prislin (Eds.), pp. 3-15.

Ross, A. (2010). Preliminary Report of the project "Border Crossings, Moving Borders: Young peoples' constructions of identities in the Baltic countries in the early $21^{\text {st }}$ Century". Manuscript. Tallinn: Jaan Tõnisson Institute.

Sowell, E. J. (2005). Curriculum. An Integrative Introduction. Upper Saddle River, New Jersey, Columbus, Ohio: Pearson Merrill/ Prentice Hall.

Taba, H. (1962). Curriculum development; theory and practice. New York: Harcourt, Brace \& World.

Vickers, E. (2005). In search of an Identity. Hong Kong: Comparative education Research Centre.

Winterson, J. (2001). The Powerbook. London: Vintage. 